\title{
Determination of some thermal properties of advanced ceramics doped with rare earth ion $\mathrm{Ce}^{4+}$
}

\author{
Betini, E. G. ${ }^{1}$; Cavichini, A. S ${ }^{1}$; Orlando, M. T. D. ${ }^{1}$; Depianti, J.B. ${ }^{2}$ \\ 1 Programa de Pós-Graduação em Engenharia Mecânica, Universidade Federal do Espírito Santo, Vitória, ES, Brasil \\ 2 Departamento de Gemologia, Universidade Federal do Espírito Santo, Vitória, ES, Brasil
}

\begin{abstract}
The main thermal properties of ceramics with double perovskite structure were investigated by relating these properties with their microstructural characteristics. The results define important parameters on the durability at high temperatures, creep resistance and greater understanding of heat transport in porous media. The samples $\mathrm{Ca}_{2} \mathrm{MnReO}_{6}$ and $\mathrm{Ca}_{1 .} \mathrm{Ce}_{0.2} \mathrm{MnReO}_{6}$ repaired using the technique of solid state reaction were studied here. Images obtained by scanning electron microscopy made it possible to evaluate the average size of junctions between grains. To evaluate this average particle size was carried out a statistical survey of the size of the junctions between grains. Taking the histograms produced, it was fitted a curve of a statistical gamma distribution density range. We observed that $\mathrm{Ca}_{2} \mathrm{MnReO}_{6}$ showed greater average size of junctions. The Laser Flash method was used to study the thermal diffusivity. A low value of thermal diffusivity equal to $(0,27 \pm 0,09) \cdot 10-7\left(\mathrm{~m}^{2} / \mathrm{s}\right)$ for sample undoped and a 5 -fold higher value for doped with cerium sample was observed. This difference was associated with high porosity and a larger average size of the junction to $\mathrm{Ca}_{2} \mathrm{MnReO}_{6}$ sample.
\end{abstract}

Keywords: ceramic, double perovskite, laser flash method, thermal properties, rare earth, cerium.

\section{Introduction}

Oxides with perovskite structure are part of the family of ceramic materials, and an ideal cubic symmetry described by the space group $\mathrm{Pm} 3 \mathrm{~m}$. The interest in this type of structure is due its thermal, magnetic, optical and electrical properties and their possible application in gas sensors, thermoelectric batteries, fuel cells and as catalysts for the decomposition and oxidation of $\mathrm{CO}, \mathrm{CO}_{2}$ and $\mathrm{CH}_{4}[1]$.

Samples of double perovskites $\mathrm{Ca}_{2} \mathrm{MnReO}_{6}$ and $\mathrm{Ca}_{1.8} \mathrm{Ce}_{0.2} \mathrm{MnReO}_{6}$ were studied based on measurements of X-ray diffraction [2], scanning electron microscopy, percentage of porosity and thermal diffusivity.

To better understand the main thermophysical properties of these materials we investigate the thermal diffusivity, thermal conductivity and specific heat as a function of temperature using the Laser Flash Method (LFM).

Among the methods of transient heat the LFM proves more advantageous for simultaneously obtaining important thermodynamic parameters in a short time interval. In this method, a flash of energy, intense and short, is applied evenly on the face of a small sample. The pulse energy diffuses unidirectionally to the opposite face to give a record of the transient temperature rise on this face [3]. To the data obtained then we have the value of thermal diffusivity for samples and then obtains thermal conductivity and specific heat by the equation:

$$
\alpha=\frac{k}{\rho c_{p}}
$$

where: $\alpha=$ thermal diffusivity $\left(\mathrm{m}^{2} / \mathrm{s}\right), \mathrm{k}=$ thermal conductivity $(\mathrm{W} / \mathrm{mK}), \rho=$ density $\left(\mathrm{kg} / \mathrm{m}^{3}\right)$ and $\mathrm{c}_{\mathrm{p}}=$ specific heat at constant pressure $(\mathrm{J} / \mathrm{kgK})$.

\section{Experimental}

The samples were prepared by solid state reaction in a sealed quartz tube where stoichiometric quantities of $\mathrm{CaO}, \mathrm{MnO}_{2}, \mathrm{ReO}_{2}$ and $\mathrm{CeO}_{2}$ in powder form were mixed, as shown by Depiante [2].

Structural characterization of all samples was analyzed by $X$ ray powder diffraction patterns taken using Rigaku diffractometer Ultima IV with Cu-Ka radiation.

The microstructure of the particles and their average junction length were determined using images from 
scanning electron microscope (SEM) model ZEISS EVO 40.

The thermal diffusivity measurements were made using the experimental arrangement shown in Figure 1.

\section{According to ASTM E1461-01 [4] for triangular pulses}

correction value of the thermal diffusivity can be obtained by the equation:

$$
\alpha=\frac{K_{1} L^{2}}{K_{2} t_{x}-\tau}
$$

where: $t_{\mathrm{x}}$ is the time for an increase of $\mathrm{x} \%$ of the temperature, $\tau$ lenght of the pulse energy and $K_{1}$ and $K_{2}$ are constants correction.

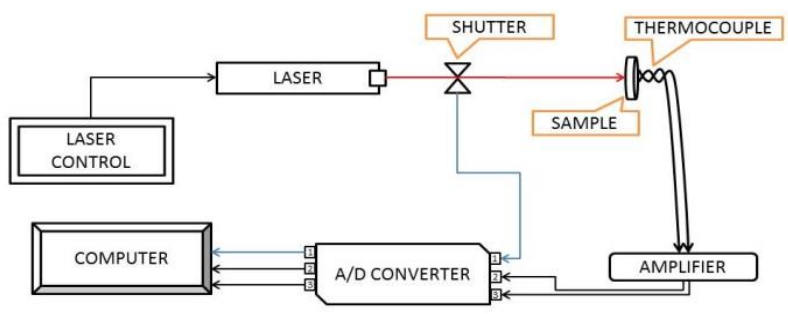

Figure 1: Homemade setup used on thermal diffusivity measurements.

\section{Results and discussion}

Rietveld analysis of powder diffraction pattern showed presence of $\mathrm{CeO} 2$ in the $\mathrm{Ca}_{1.8} \mathrm{Ce}_{0.2} \mathrm{MnReO}_{6}$ resulting in $\mathrm{Ca}_{1.92} \mathrm{Ce}_{0.08} \mathrm{MnReO}_{6}$ stoichiometry as explained by Depianti and co-works [2].

In the micrographs by SEM we observed that both samples had a homogenous microstructure with regard to the form and size of the particles. The average size of the junctions obtained from a Gamma distribution can be seen in Table 1.

Table 1: Average junction length of the samples [6].

\begin{tabular}{|c|c|}
\hline Sample & $<\mathbf{d}>(\boldsymbol{\mu m})$ \\
\hline $\mathrm{Ca}_{2} \mathrm{MnReO}_{6}$ & $2,79 \pm 0,06$ \\
\hline $\mathrm{Ca}_{1,92} \mathrm{Ce}_{0,08} \mathrm{MnReO}_{6}$ & $2,42 \pm 0,04$ \\
\hline
\end{tabular}

The results of the thermophysical measurements using a Laser Flash method can be seen in Table 2 .

Table 2: Measurement Thermal of the samples by Laser Flash method.

\begin{tabular}{|c|c|c|c|}
\hline Sample & $\begin{array}{c}\alpha \\
\left(.10^{-7} \mathrm{~m}^{2} / \mathrm{s}\right) \\
\end{array}$ & $\begin{array}{c}k \\
\left(.10^{4} \mathrm{~W} / \mathrm{m} . \mathrm{k}\right) \\
\end{array}$ & $\begin{array}{c}c \\
(\mathrm{~J} / \mathrm{kg} . \mathrm{K}) \\
\end{array}$ \\
\hline $\mathrm{Ca}_{2} \mathrm{MnReO}_{6}$ & $0,27 \pm 0,09$ & $0,6 \pm 0,2$ & $0,92 \pm 0,09$ \\
\hline $\begin{array}{c}\mathrm{Ca}_{1,{ }_{2} 2} \mathrm{Ce}_{0,08} \mathrm{Mn} \\
\mathrm{ReO} \mathrm{O}_{6} \\
\end{array}$ & $1,4 \pm 0,3$ & $1,5 \pm 0,4$ & $0,3 \pm 0,03$ \\
\hline
\end{tabular}

In agreement with the measurements of apparent porosity (AP\%) [5] and specific mass [6], we observed that the $\mathrm{Ca}_{2} \mathrm{MnReO}_{6}$ sample has lower density $(2,37$ $\pm 0,03) \cdot 10^{3}\left(\mathrm{~kg} / \mathrm{m}^{3}\right)$ and apparent porosity (AP\%) equal to $28,2 \%$. For Ce-doped sample were observed a higher density $(3.57 \pm 0.01) .10^{3}\left(\mathrm{~kg} / \mathrm{m}^{3}\right)$ and only $9.4 \%$ empty space, taking into account uncertainty of $0.8 \%$ for both measures of the AP\%.

\section{Conclusions}

The thermal measurements showed very low values of thermal diffusivity and thermal conductivity associated with a high value of specific heat for the compound $\mathrm{Ca}_{2} \mathrm{MnReO}_{6}$. These values are not in agreement with the literature. The reason for this decrease may be related to the high pulse time $\tau$ measures the thermal diffusivity by LFM. We also take into account smaller number of junctions and high apparent porosity found in this compound leading to low values of $\alpha$ and $k$.

\section{Acknowledgements}

We acknowledgments to CAPES and FAPES for financial support.

\section{References}

[1] Ribeiro, J. P.; Oliveira, R. M. P. B.; P.M. Pimentel, R.M.P.B. Oliveira, D.M.A.Melo,T. B. Síntese e estudo microestrutural de perovsquitas tipo $\mathrm{La} 0,8 \mathrm{Ca} 0,2 \mathrm{MO} 3$ (M: Co e Mn) para aplicação em catálise automotiva. Cerâmica, v. 57, p. 348-351, 2011.

[2] Depianti, J. B. M. T. D. Orlando. A. S. Cavichini, H. P. S. Corrêa, V. A. Rodrigues, J. L. Passamai, E. L.O Piedade, H. Belich, E. F. Medeiros, F. C. L.de Melo. Structural and magnetic investigation of $\mathrm{Ca} 2 \mathrm{MnReO} 6$ doped with Ce. Cerâmica, v. 59, p. 262-268, 2013

[3] W. J. Parker, R.J. Jenkins, C.P. Butler, G.L. Abbott, Flash Method of Determining Thermal Diffusivity, Heat, Capacity and Thermal Conductivity. J. Appl. Phys., vol.32, n. 9, pp. 1679-1684, 1961.

[4] ASTM. Standard Test Method for Thermal Diffusivity by the Flash Method. ASTME1461. ASTM International, v. $88,2001$.

[5] ASTM. Standard Test Method for Water Absorption, Bulk Density , Apparent Porosity, and Apparent specific Gravity of Fired Whiteware Products. ASTM C373-88. ASTM International. 88, n. Reapproved 2006, p. 40-41, 2013.

[6] Betini, E. G., Determinação de algumas propriedade térmicas de cerâmicas avançadas dopadas com o íon terra rara Ce4+. Vitória. Dissertação de Mestrado. Programa de Pós Graduação em Engenharia Mecânica da UFES. Universidade Federal do Espirito Santo, 2013. 